\title{
Single Incision Laparoscopic Cholecystectomy without a Camera Operator
}

YoungRok Choi, M.D., Ho-Seong Han, M.D., Ph.D., Yoo-Seok Yoon, M.D., Ph.D., Jae Young Cho, M.D., Ph.D., Jae Yool Jang, M.D., Han Lim Choi, M.D., Jae Seong Jang, M.D., Seong Uk Kwon, M.D., Sungho Kim, M.D., Jangkyu Choi, M.D. Department of Surgery, Seoul National University Bundang Hospital, Seoul National University College of Medicine, Seongnam, Korea

Purpose: This study aimed to evaluate the implementation of solo surgery using a laparoscopic scope holder for single incision laparoscopic cholecystectomy (SILC).

Methods: With a glove port and a flexible high-definition scope, SILC was performed through a single trans-umbilical incisional site with $\mathrm{CO} 2$ pneumoperitoneum at a pressure of $12 \mathrm{mmHg}$. Fiftyeight patients who underwent solo SILC using a scope holder (Solo-SILC) were compared to 15 patients who underwent camera operator-assisted SILC (Ca-SILC) in terms of intraoperative and postoperative outcomes.

Results: The mean BMI and operation time were $23.0 \pm 3.6 \mathrm{~kg} / \mathrm{m}^{2}$ and $64.4 \pm 16.6 \mathrm{~min}$ in Ca-SILC and $25.0 \pm 3.8 \mathrm{~kg} / \mathrm{m}^{2}$ and $58.2 \pm 27.1 \mathrm{~min}$ in Solo-SILC, respectively $(p=0.067$ and $p=0.410)$. Estimated blood loss was negligible and an additional assistant port was not required in either groups. A case of gallbladder perforation and bile leak was noted in the Ca-SILC group, and 13 cases of bile leak in the Solo-SILC group, with no significant differences ( $p=0.167)$ during the surgery. Postoperative outcomes including surgical complications, diet restriction, diarrhea and hospital stay were not significantly different except for shoulder pain $(p<0.001)$.

Conclusion: Even with the limitations of a small number of patients, Solo-SILC proved to be a feasible technique. To confirm the safety of solo-SILC, further studies with a larger sample size are required.

Keywords: Laparoscopic cholecystectomy, Surgical wound, Minimally invasive surgical procedures

This is an Open Access article distributed under the terms of the Creative Commons Attribution Non-Commercial License (http:// creativecommons.org/licenses/by-nc/4.0/) which permits unrestricted non-commercial use, distribution, and reproduction in any medium, provided the original work is properly cited.
Received April 6, 2017

Revised 1st May 8, 2017 2nd June 1, 2017

Accepted June 2, 2017

Corresponding author

Ho-Seong Han

Department of Surgery, Seoul

National University Bundang

Hospital, 82, Gumi-ro, 173 Beon-gil,

Bundang-gu, Seongnam 13620,

Korea

Tel: +82-31-787-7091

Fax: +82-31-787-4055

E-mail: hanhs@snubh.org

\section{INTRODUCTION}

Laparoscopic cholecystectomy is the most common surgery in the hepatobiliary-pancreas field and has become the gold standard treatment for benign gallbladder diseases because this procedure is associated with reduced surgical trauma and improves postoperative recovery in patients. With developments in laparoscopic knowledge and techniques, surgeons have tried to develop less invasive cholecystectomy proce- dures. Since single incision laparoscopic cholecystectomy (SILC) was described in 1997 by Navarra et al., ${ }^{1}$ several randomized controlled trials have shown that SILC is a safe procedure with beneficial cosmetic effects. ${ }^{2-5}$

However, SILC lead to the lack of triangulation in a procedure, in addition to crowding of instruments and their crossover, as well as handing articulation of laparoscopic instruments in an awkward position for the surgeon. Moreover, due to the difficulties in obtaining a safe and critical view, SILC 
is not popular among surgeons. Recently improved optics, articulate instruments, and specially designed ports have facilitated single-incision surgery. ${ }^{6}$ Along with these, the increased demand in young patients for better cosmetic outcomes with minimally invasive interventions play a significant role in reviving SILC.

A stable operative view is essential in an awake operator position with instrument crowding during SILC. We performed SILC using a novel method, facilitating stable surgical view without a camera operator by utilizing a laparoscopic camera holder and accustomed laparoscopic straight instruments. We report our initial experiences as well as the clinical outcomes of this solo SILC.

\section{MATERIALS AND METHODS}

Between July 2014 and June 2015, SILC was performed in 73 patients at a single center. Fifty-eight procedures of SILC were performed with a scope holder and no assistant (SoloSILC), while the remaining were performed with a camera operator (Ca-SILC). SILC was considered for selected patients who were scheduled to undergo cholecystectomy for benign gallbladder diseases; including gallbladder stone, polyp, adenomyomatosis and cholecystitis. All SILCs were performed by a single surgeon, who was experienced in over 300 cases of three-port laparoscopic cholecystectomy before performing their $1^{\text {st }}$ SILC. Solo surgery was performed when an experienced camera operator was not available during SILC.

Two comparable groups of patients were analyzed; SoloSILC and Ca-SILC. Data on patients' characteristics and perioperative information with postoperative symptoms were collected prospectively and analyzed retrospectively.

All statistical analyses were performed using the commercial software, SPSS for windows (version 21.0: SPSS, Chicago IL, USA). The data values were presented as mean \pm standard deviation. A $p$ value of $\leq 0.05$ was considered statistically significant.

\section{Surgical procedures}

The patient was placed in a lithotomy position with a reverse Trendelenburg and a left lateral tilt. The operator was positioned between patient's legs during main procedures. A longitudinal 2 3 cm sized trans-umbilical incision was made. After the peritoneal cavity was directly visualized, a Glove port (Nelis, Bucheon-si, Gyeonggi-do, Korea) was placed at the incision site. The abdominal cavity was inflated with carbon dioxide at a pressure of $12 \mathrm{mmHg}$. An available $5 \mathrm{~mm}$ or $10 \mathrm{~mm}$ flexible laparoscopic camera (Endoeye flexible HD camera system; Olympus Medical Systems Corp., Tokyo, Ja-

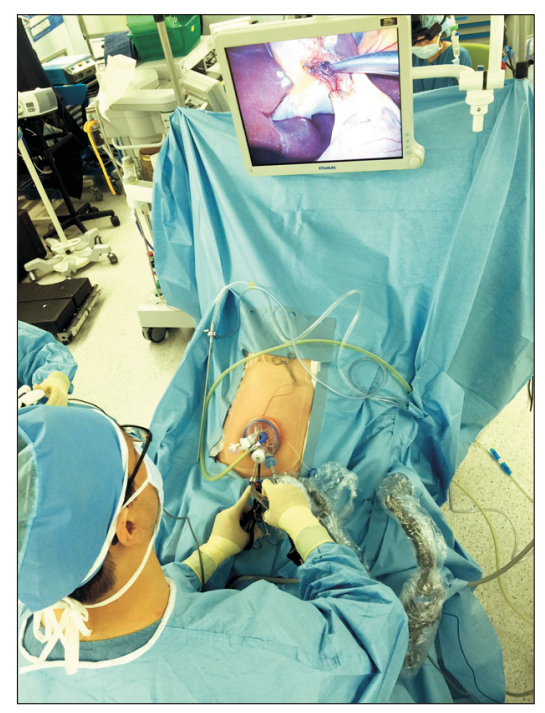

Fig. 1. Solo-Single Incision Laparoscopic Cholecystectomy.

pan) was inserted into the abdominal cavity through a hole in the glove port, and was fixed subsequently with a scope holder (Laparostat $^{\mathrm{TM}}$, CIVCO medical Solutions, IA, USA) in SoloSILC. The surgical view was adjusted by moving the camera holder manually by a surgeon. In cases of Ca-SILC, a camera operator joined the operation without a laparoscopic camera holder. The conventional straight laparoscopic instruments were used in both groups as in multi-port laparoscopic cholecystectomy (Fig. 1).

The GB body was tracked in the 9 11 o'clock direction using trans-abdominal sutures with $1 \sim 0$ prolene in the first 48 cases. The subsequent SILCs were performed without traction sutures. After isolating and dividing the cystic duct and cystic artery, a GB was dissected from the liver and extracted through the Glove port. Next, the umbilical port site was repaired using interrupted sutures in the fascia layer with only 1 2 intradermal sutures at both ends of the skin incision site for skin closure and drainage for fluid collection.

\section{Postoperative wound and symptomatic assessment}

The wounds were classified into three groups arbitrarily: grade I; clear, grade II; wound erythema or induration with pain, grade III; pus drainage. The amount of diet, diarrhea, and pain (abdomen, back and shoulder) were investigated 2 weeks after the operation at the outpatient clinic and these factors were compared between both groups after scoring according to the contents. Diet restriction was classified into mild (I): suboptimal appetite, moderate (II): digestive aid needed and severe degree (III): abdominal discomfort. Newly developed diarrhea after the operation was classified into mild 
(I): relieved within 3 days, moderate (II): relieved within 7 days and severe (III): when anti-diarrhea drug was required. Post-cholecystectomy right shoulder pain was classified into mild (I): pain relieved within postoperative 3 days, moderate (II): within 7 days and severe (III): over 7 days.

\section{RESULTS}

\section{Patient characteristics}

Fifteen patients including 3 men and 12 women were present in the Ca-SILC group, and 58 patients including 22 men and 36 women were in the Solo-SILC group. Their mean

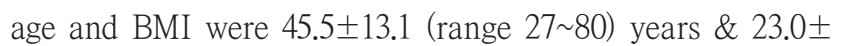
3.6 (range 17.9 31.9) kg/m ${ }^{2}$ in Ca-SILC and $46.7 \pm 12.7$ (range 20 80) years \& 25.1 \pm 3.8 (range 18.3 35.9) $\mathrm{kg} / \mathrm{m}^{2}$ Solo-SILC $(p=0.759$ and $p=0.067)$ (Table 1). The main surgical indications based on images and physical examination with laboratory findings were chronic cholecystitis $(\mathrm{n}=2)$ and symptomatic $\mathrm{GB}$ stones ( $\mathrm{n}=13)$ in $\mathrm{Ca}-\mathrm{SILC}$, cholecystitis including acute cholecystitis, chronic cholecystitis and gangrenous cholecystitis $(n=19)$, symptomatic GB stones $(n=38)$ and GB polyp $(n=1)$ in Solo-SILC. One case in Ca-SILC, and three in Solo-SILC were emergency cases.
Preoperative common bile duct stone removal with sphincterotomy and endoscopic retrograde biliary drainage or pancreatic duct drainage was performed for three patients (20\%) in the Ca-SILC group and those with percutaneous gallbladder drainage for 6 patients (10.3\%) in the Solo-SILC group. In $\mathrm{Ca}-\mathrm{SILC}$, four patients had a previous history of abdominal operation: Hartmann operation due to rectal perforation $(n=1)$, low anterior resection for colon cancer $(\mathrm{n}=1)$, Caesarian section $(\mathrm{n}=1)$ and total hysterectomy $(\mathrm{n}=1)$. In Solo-SILC, fourteen patients had a history of abdominal operation: Cesarean section $(n=3)$, gastrectomy $(n=1)$, hysterectomy $(n=3)$, low anterior resection for colon cancer $(\mathrm{n}=1)$, appendectomy for simple appendicitis \& perforated appendicitis $(n=4)$, intestinal resection due to intestinal perforation $(\mathrm{n}=1)$, and trauma accident $(\mathrm{n}=1)$.

\section{Surgical outcomes}

No conversion to open surgery was necessary in either groups. A drainage catheter was inserted in three patients in the Solo-SILC group, but it did not show any statistical significance. Mean operation time was $64.4 \pm 16.6$ (range 30 90) min in Ca-SILC, and 58.2 27.1 (range 25 190) $\mathrm{min}$ in Solo-SILC $(p=0.410)$. The estimated blood loss was traced and no additional laparoscopic assistant port was needed in either groups.

Table 1. Preoperative patients' characteristics

\begin{tabular}{lccc|}
\hline & Ca-SILC, $\mathrm{n}=15$ & Solo-SILC, $\mathrm{n}=58$ & $p$ value \\
\hline Age (years) & $45.5 \pm 13.1$ & $46.7 \pm 12.7$ & 0.759 \\
\hline Gender $(\mathrm{M}: \mathrm{F})$ & $3(20 \%): 12(80 \%)$ & $22(37.9 \%): 36(62.1 \%)$ & 0.197 \\
\hline BMI $\left(\mathrm{kg} / \mathrm{m}^{2}\right)$ & $23.0 \pm 3.6$ & $25.1 \pm 3.8$ & 0.067 \\
\hline ASA score & $1.3 \pm 0.5$ & $1.3 \pm 0.5$ & 0.875 \\
\hline Diseases & & & 0.234 \\
$\quad$ GB stone & 13 & 38 & \\
Cholecystitis & 2 & 19 & \\
GB polyp & $1(6.7 \%)$ & 1 & 0.824 \\
\hline Emergency cholecystectomy & & $3(5.2 \%)$ & \\
Preoperative biliary procedure & $2(13.3 \%)$ & $14(24.1 \%)$ & 0.374 \\
ERCP; CBD stone removal & $1(6.7 \%)$ & $3(5.1 \%)$ & 0.824 \\
ERBD or ERPD & 0 & $6(10.3 \%)$ & 0.199 \\
PTGBD & $4(26.7 \%)$ & $14(24.1 \%)$ & 0.842 \\
\hline Abdominal operation history & & & \\
\hline
\end{tabular}

Solo-SILC = Solo single-incision laparoscopic cholecystectomy; Ca-SILC = camera operator-assisted SILC; $M=$ male; $F=$ female; $\mathrm{Ht}=$ height; $\mathrm{Wt}=$ weight; $\mathrm{BMI}=$ body mass index; $\mathrm{ASA}=$ American Society of Anesthesiology classification; $\mathrm{ERCP}$ = endoscopic retrograde cholangio-pancreatography; ERBD = endoscopic retrograde biliary drainage; $\mathrm{EPBD}=$ endoscopic pancreatobiliary drainage; $\mathrm{CBD}=$ common bile duct; PTGBD = percutaneous transhepatic gallbladder drainage. 
Table 2. Operative findings

\begin{tabular}{|c|c|c|c|}
\hline & Ca-SILC, n= 15 & Solo-SILC, $n=58$ & $p$ value \\
\hline Conversion to open surgery & 0 & 0 & \\
\hline Drain catheter insertion & 0 & 3 & 0.375 \\
\hline GB traction suture(s) & $13(86.7 \%)$ & $34(63.0 \%)$ & 0.044 \\
\hline Operation time (range) & $64.4 \pm 16.6$ (30 90) & $58.2 \pm 27.1(25 \sim 190)$ & 0.410 \\
\hline Estimated blood loss & Trace & Trace & \\
\hline Additional port & 0 & 0 & \\
\hline Histologic acute cholecystitis & 0 & 9 & 0.103 \\
\hline Biliary complications & & & 0.164 \\
\hline GB perforation with Bile leak & $1(6.7 \%)$ & $13(22.4 \%)$ & \\
\hline Bile duct injury & 0 & 0 & \\
\hline Bleeding in GB bed & 0 & 0 & \\
\hline \multicolumn{4}{|l|}{ GB stone } \\
\hline Total number of stone & $18.9 \pm 34.6(1 \sim 121)$ & $38.2 \pm 141.6$ (1 numerous $)$ & 0.616 \\
\hline Maximum size of stone $(\mathrm{mm})$ & $8.2 \pm 6.4(2 \sim 20)$ & $9.3 \pm 8.1(1 \sim 30)$ & 0.712 \\
\hline
\end{tabular}

$\mathrm{GB}=$ gallbladder; Solo-SILC $=$ Solo single-incision laparoscopic cholecystectomy; Ca-SILC = camera operator-assisted SILC.

One case (6.6\%) of GB perforation with bile leak occurred in the Ca-SILC group and 13 cases (22.4\%) occurred in the SoloSILC group during gallbladder dissection from the liver, with no significant difference between the two groups $(p=0.164)$. There was no difference in the number of gall bladder stones or its maximal size between the two groups either (Table 2).

Surgical wounds were clear in all Ca-SILC patients, but two patients had an inflamed wound and one patient showed wound discharge in Solo-SILC $(p=0.405)$. Post-cholecystectomy diet restriction and diarrhea were not significantly different; diet restriction grade [I $(n=10,66.7 \%)$, II $(n=5,33.3 \%)$, III $(\mathrm{n}=0)$ in Ca-SILC, versus I $(\mathrm{n}=41,70.7 \%)$, II $(\mathrm{n}=14,24.1 \%)$, III $(n=3,5.2 \%)$ in Solo-SILC ( $p=0.944)]$, post-cholecystectomy diarrhea [I $(n=13,86.7 \%)$, II $(n=2,13.3 \%)$ in Ca-SILC, versus I $(n=45,77.6 \%)$, II $(n=11,19.0 \%)$, III $(n=2,3.4 \%)$ in Solo-SILC $(p=0.378)]$.

Shoulder pain was severe in the Ca-SILC group which was significantly higher than the Solo-SILC group $(p<0.001)$; [I $(\mathrm{n}=7,46.7 \%)$, II $(\mathrm{n}=5,33.3 \%)$, III $(\mathrm{n}=3,20.0 \%)$ in $\mathrm{Ca}-\mathrm{SILC}$, versus I $(n=48,82.8 \%)$, II $(n=10,17.2 \%)$, III $(n=0)$ in Solo-SILC] (Table 3).

\section{DISCUSSION}

The significantly reduced operation time and the use of fewer assistants seem to be important factors, particularly in times of limited surgical manpower. These current requirements for minimally invasive surgery have given rise to solo surgery for single incision laparoscopic cholecystectomy. Solo-SILC can significantly reduce the need for manpower resources.

Single incision laparoscopic cholecystectomy is difficult because a surgeon has to perform surgery under a limited surgical field with restricted instruments. Another obstacle is unstable surgical view because of an unexperienced camera operator, which can lead to positional struggle over the narrow surgical field to control the camera and instruments through the single opening between the camera assistant and operator.

By introducing a laparoscopy scope holder, an operator does not need to negotiate with an assistant to create a good position and one can obtain a stable surgical view constantly without a conflict between the operator and the surgeon in the narrow surgical field. For this reason, it is easier to apply solo surgery for single incision laparoscopic cholecystectomy.

The authors wanted to investigate the feasibility of using Solo-SILC as a replacement for Ca-SILC as well as multi-port laparoscopic cholecystectomy. A passive camera holder was maneuvered by the surgeon's hand during the operation. Even though the surgical view is not capricious during cholecystectomy, it is unlikely to perform the operation safely without an assistant. During SILC, at least two instruments and a camera tend to conflict each other through a single port. Unfamiliar crossing of instruments results in inadequate tractions, difficult exposure of hilar structure and uncomfortable position of a surgeon. Although articulated and curved instruments 
Table 3. Postoperative results

\begin{tabular}{|c|c|c|c|}
\hline & Ca-SILC, n= 15 & Solo-SILC, $n=58$ & $p$ value \\
\hline Hospital stay & $1.5 \pm 0.8$ & $1.9 \pm 1.8$ & 0.824 \\
\hline \multicolumn{4}{|c|}{ Post-cholecystectomy symptoms } \\
\hline Diet restriction & & & 0.944 \\
\hline । & $10 \mid 66.7 \%)$ & $41(70.7 \%)$ & \\
\hline$\|$ & $5(33.3 \%)$ & $14(24.1 \%)$ & \\
\hline III & & $3(5.2 \%)$ & \\
\hline Diarrhea & & & 0.378 \\
\hline । & $13(86.7 \%)$ & $45(77.6 \%)$ & \\
\hline$\|$ & $2(13.3 \%)$ & $11(19.0 \%)$ & \\
\hline III & & $2(3.4 \%)$ & \\
\hline Shoulder pain & & & $<0.001$ \\
\hline । & $7(46.7 \%)$ & $48(82.8 \%)$ & \\
\hline$\|$ & $5(33.3 \%)$ & $10(17.2 \%)$ & \\
\hline III & $3(20.0 \%)$ & & \\
\hline Wound Complications & & & 0.405 \\
\hline । & $15(100 \%)$ & $55(94.8 \%)$ & \\
\hline$\|$ & & $2(3.4 \%)$ & \\
\hline III & & $1(1.7 \%)$ & \\
\hline Clavien-Dindo Classification & & & 0.824 \\
\hline । & $5(33.3 \%)$ & $22(37.9 \%)$ & \\
\hline$\|$ & $10(66.7 \%)$ & $32(55.2 \%)$ & \\
\hline Illa & & $3(5.2 \%)$ & \\
\hline$\| l l b$ & & $1(1.7 \%)$ & \\
\hline
\end{tabular}

Solo-SILC = Solo single-incision laparoscopic cholecystectomy; Ca-SILC = camera operator-assisted SILC; Wound: grade I = clear; grade II = erythematous or with induration and pain; grade III = with pus drainage. Diet: good = mild (I) with a suboptimal appetite; moderate $(I I)=$ digestives required; severe degree (IIII) = with abdominal discomfort even with digestives. Diarrhea: mild (II) = relieved within 3 days; moderate $(I I)=$ relieved within 7 days; severe (IIII) = an anti-diarrhea drug is needed. Post-cholecystectomy abdominal and right shoulder pain was classified as mild (I) = pain relieved within 3 postoperative days; moderate (II) = pain relieved within 7 days; severe $(I I I)=$ pain relieved after 7 days.

were introduced to solve these problems, the impact of these instruments has been limited. ${ }^{8}$ We used the same straight instruments, which are used in multi-port cholecystectomy. An operation through a single incision using only rigid instruments in the co-axial position would be challenging ${ }^{9}$; however, we could perform cholecystectomy with the fewest moves because a flexible camera was enabled to decrease the conflicts of instruments and generated the surgical views from various angles which were safe as per the standards reported by Strasberg. ${ }^{10}$

We apply a small incision with the less than $2 \mathrm{~cm}$ for $\mathrm{se}^{-}$ lected patients, but usually $2.5 \mathrm{~cm}$ under the parallel method.
Incision length was extended according to the relaxation status of the abdominal wall.

The operation time was not significantly different between the two groups, but maximum operation time in Solo-SILC was 190 minutes. However, this case was Solo-SILC operation for Mirrizi syndrome, in which the impacted cystic duct stone compressed the common bile duct pathway accompanied with severe inflammation. In the operative findings, gall bladder perforation rate was higher in the Solo-SILC group. In the early period, suture perforation was observed. Without the suture traction, the failure to control the distance of the instrument under the parallel methods might be shown. This was 
solved by overcoming the learning curve due to the failure to control the distance by the parallel method.

Intraoperative and postoperative complications except shoulder pain were not statistically different between the two groups. The Solo-SILC group showed higher pain intensity, but we could not conclude that Ca-SILC was better with respect to post-operative shoulder pain because of the small number of cases in this report. In Solo-SILC, two cases experienced three different Clavien-Dindo IIIa complications involving postoperative removal of common bile duct stone and percutaneous drainage during catheter insertion for collection of abdominal fluid. One case with a Clavien-Dindo IIIb complication was due to incorrect clipping in the common bile duct during operation. Postoperative total bilirubin was elevated, and the endoscopic retrograde cholangiography showed total occlusion of common bile duct in this patient. During re-operation, the operator removed the clips after which the patient recovered and was discharged.

The limitations of this study are the selection bias, arbitrary indication for solo surgery and a small number of cases. Nevertheless, this study showed that results of solo surgery were comparable to that of the camera operator assisted surgery for single incision laparoscopic cholecystectomy with conventional straight instruments. Even with the limitations of the small number of patients, Solo-SILC was shown to be a feasible technique requiring fewer overall personnel resources. To confirm the safety of solo-SILC, further studies with a larger sample size are required.

\section{REFERENCES}

1) Navarra G, Pozza E, Occhionorelli S, Carcoforo P, Donini I. Onewound laparoscopic cholecystectomy. Br J Surg 1997;84:695.

2) Tsimoyiannis EC, Tsimogiannis KE, Pappas-Gogos G, et al. Dif- ferent pain scores in single transumbilical incision laparoscopic cholecystectomy versus classic laparoscopic cholecystectomy: a randomized controlled trial. Surg Endosc 2010;24:1842-1848.

3) Marks J, Tacchino R, Roberts $K$, et al. Prospective randomized controlled trial of traditional laparoscopic cholecystectomy versus single-incision laparoscopic cholecystectomy: report of preliminary data. Am J Surg 2011;201:369-372; discussion 372-363.

4) Markar SR, Karthikesalingam A, Thrumurthy S, Muirhead L, Kinross J, Paraskeva P. Single-incision laparoscopic surgery (SILS) vs. conventional multiport cholecystectomy: systematic review and meta-analysis. Surg Endosc 2012;26:1205-1213.

5) Phillips MS, Marks JM, Roberts K, et al. Intermediate results of a prospective randomized controlled trial of traditional four-port laparoscopic cholecystectomy versus single-incision laparoscopic cholecystectomy. Surg Endosc 2012;26:1296-1303.

6) Deveci U, Barbaros U, Kapakli MS, et al. The comparison of single incision laparoscopic cholecystectomy and three port laparoscopic cholecystectomy: prospective randomized study. J Korean Surg Soc 2013;85:275-282.

7) Gillen S, Pletzer B, Heiligensetzer A, et al. Solo-surgical laparoscopic cholecystectomy with a joystick-guided camera device: a case-control study. Surg Endosc 2014;28:164-170.

8) Cha MG, Kim TS, Kim KH, An CH, Kim JS. The Effectiveness of a Snake Liver Retractor during Needlescopic Grasper Assisted Sinlge-Incision Laparoscopic Cholecystectomy in the Aspect of Securing a Critical View of Safety. J Minim Invasive Surg 2013;16: 34-38.

9) Saber AA, El-Ghazaly TH, Dewoolkar AV, Slayton SA. Singleincision laparoscopic sleeve gastrectomy versus conventional multiport laparoscopic sleeve gastrectomy: technical considerations and strategic modifications. Surg Obes Relat Dis 2010;6:658-664.

10) Strasberg SM, Hertl M, Soper NJ. An analysis of the problem of biliary injury during laparoscopic cholecystectomy. J Am Coll Surg 1995;180:101-125. 